with which I am familiar, however, include all the useful tricks, and the others have an authoratitive look about them.

The first section of the book consists of procedures for the isolation of membranes, and includes chapters on Mycoplasma membranes (Razin and Rottem), surface membranes (Neville), mitochondrial membranes (Sottocasa), endoplasmic reticulum (De Pierre and Dallner) and nuclear membranes (Harris and Agutter). The only pity here is that there is nothing on membranes of bacteria such as Escherichia coli or on micro-organisms such as Tetrahymena, both of which are proving of importance in studying correlations between membrane structure and function.

The second section of the book is concerned more with the analysis of membranes, and includes chapters on the solubilisation of membranes (Maddy

\section{Transition metal compounds}

Methodicum Chimicum. Volume 8: Preparation of Transition Metal Derivatives. Edited by Kurt Neidenzu and Hans Zimmer. Pp. $x+579$. (Academic: New York, San Francisco and London, 1976.) \$110; £67.10.

THIS text details published and proven methods for the preparation of transition metal compounds. In general, one chapter is devoted to each of the thirty d-transition elements; the lanthanide and actinide groups of elements each merit one chapter, a summary of ferrocene chemistry is included; and aspects of carbonyl, metallocene, and heteropolyanion chemistries are reviewed separately. The material for each chapter is classified in order of increasing oxidation state, a reasonably good index is provided and no real difficulty should be encountered in using the volume as a reference source. Each chapter is referenced in a reasonably comprehensive manner and nearly 7,000 original publications and review articles are cited in all. Some 29 authors have made one or more contributions, and, in several instances, these chemists are internationally recognised as authorities on their chosen topic.

Despite the considerable collective talent and effort involved in the preparation of this work, however, several reservations must be expressed when considering a recommendation to purchase this expensive volume. The most serious of these reservations results from the inherent nature of this work, which attempts to describe contemporary synthetic transition metal chemistry and Dunn) and on the analysis of membrane proteins (Dunn and Maddy), lipids (Veerkamp and Broekhuyse) and carbohydrates (Cook). These are followed by some more peripheral, but no less interesting chapters on the applications of phospholipases (Zwaal and Roelofsen), on immunochemical gel precipitation techniques (Bjerrum and Bog-Hansen) and on protein labelling (Hubbard and Cohn).

It is perhaps a sign of how far the study of membranes has progressed that a book of this kind can be written; and there can be few working with membranes who would not gain by browsing through it. Finally, there is a coherence about the book which it is rare to find in an edited volume, and for which the editor deserves high praise.

A. G. Lee

Dr Lee is a lecturer in the Department of Physiology and Biochemistry at the University of Southampton, UK.

in less than 600 pages. Since the space devoted to a particular element is no more than fifteen pages, the book reads like a laundry list. The description of the preparation of any particular compound, or group of compounds, is covered in one sentence of the 'add A to B to produce C' variety, with no details of the yield, purification procedure(s), necesary precautions, or properties of the compound(s) being given. As none of the material is original and the authors have been critical only in their selection of the material to be included, much of the information presented is readily accessible to the initiated inorganic chemist in standard and specialist texts and review articles. These criticisms are all the more serious since, due to certain unspecified difficulties, a considerable delay has occurred between the submission of the manuscripts and their publication, so that the coverage of the literature ends at 1970 .

This volume is an extremely useful, if somewhat outdated, reference source for synthetic routes developed for the preparation of a wide range of transition metal compounds. In view of the reservations outlined above, the inorganic research chemist could spend the amount of money involved more wisely by purchasing a collection of other texts. The non-specialist inorganic chemist, and other scientists interested in the preparation of inorganic compounds, should, however, find this compilation of considerable value.

C. David Garner

Dr Garner is a Lecturer in Inorganic Chemistry at the University of Manchester, UK.

\section{Electrophilic halogenation}

Electrophilic Halogenation. By P. B. D. de la Mare. Pp. xi+231. (Cambridge University: Cambridge, 1976.) Hardcover £10.50; softcover $£ 4.50$.

Although some discussion of the importance and mechanism of electrophilic halogenation is to be found in most undergraduate texts, there is a need for an up-to-date, detailed and unified discussion of such reactions.

In this book electrophilic halogenation is covered from a mechanistic viewpoint. It is a complex area where the problems of reactivity, regioselectivity, stereoselectivity, product multiplicity and the nature of the halogenating species all have to be taken into account. The author, who has been an active research worker in this area for some thirty years, adopts an approach which considers the formation and fate of the carbonationic species produced by attack of electrophiles in general on unsaturated compounds, both aromatic and aliphatic. The basic patterns which emerge are then elaborated for each of the halogens and their derivatives in turn. Topics such as the acid and base catalysed $\alpha$-halogenation of carbonyl compounds are covered in a chapter on miscellaneous electrophilic halogenation, and there is also a chapter on electrophilic halogenation of aromatic heterocycles. Introductory chapters provide the necessary background in physical organic chemistry and describe the halogens and their derivatives.

In keeping with the Cambridge University Texts philosophy, the level of the book is intended to suit final year undergraduate and early postgraduate students. The book contains many references to the original literature and is clearly written. It will nevertheless be demanding at the level intended, concentrating as it does on physical organic rather than descriptive aspects of the subject. The undergraduate may also feel that the area of chemistry covered for the price of the book is somewhat limited; and indeed the book may have had a wider appeal if the scope had been broadened to cover either electrophilic addition and substitution in general, or halogenation in general. The latter suggestion has much to commend it since free radical halogenation is also very important and frequently competes with the electrophilic process.

R. C. Storr

Dr Storr is a Lecturer in the Department of Organic Chemistry at the University of Liverpool, UK. 